\title{
Keragaman Sastra dan Keindonesiaan \\ Sebuah Refleksi
}

\author{
Melani Budianta*)
}

\section{FIBUI}

\begin{abstract}
Abstrak
Kesusasteraan Indonesia berakar dan tumbuh dari keragaman, sejak masa prakolonial sampai saat ini. Berbagai pengaruh lintas budaya, keragaman bahasa, aliran dan orientasi budaya mewarnai kesusasteraan yang berkembang di Indonesia. Dalam keragaman itu keindonesiaan terus menerus didialogkan dan dibangun. Meskipun demikian keragaman itu tidak bisa tidak mengandungi relasi kuasa yang tidak seimbang. Kesusasteraan dalam bahasa Indonesia yang ditulis oleh masyarakat di wilayah Indonesia Timur kurang terekam dalam sejarah kesusasteraan, kesusasteraan daerah kurang mendapat ruang untuk mendapat perhatian dan dukungan. Dengan mengoptimalkan akses terhadap kesusasteraan yang ditulis dalam bahasa Indonesia maupun daerah, kita bukan saja membangun kesusasteraan yang lebih mendunia, melainkan juga membangun keindonesiaan yang lebih inklusif.
\end{abstract}

\section{Pengantar}

Bagi sebagian besar orang Indonesia, keragamaman budaya bukanlah suatu hal yang baru, bahkan mungkin suatu kenyataan yang sudah diterima begitu saja tanpa perlu terlalu dipikirkan. Kita mungkin baru menyadari keistimewaan pluralitas itu, ketika orang lain mengomentarinya. Dalam sebuah seminar di Roma awal tahun 2009, seorang peserta mengajukan komentar atas paparan saya tentang kemajemukan Indonesia: "Dengan tujuh ratus empat belas bahasa, tiga belas ribu pulau dan tiga ratus suku bangsa, sungguh mencengangkan bahwa negara seperti Indonesia masih bisa bertahan sampai sekarang." Ketika orang mulai bertanya, apa rahasianya, barulah kita didesak untuk memikirkan hakikat kebersamaan kita sebagai suatu bangsa.

\footnotetext{
*) Guru Besar pada Fakultas Ilmu Budaya Universitas Indonesia
} 
Salah satu kuncinya, tidak bisa tidak, adalah adanya suatu bahasa perekat yang didukung oleh seluruh anak bangsa. Hal ini saya sadari ketika sedang bertandang ke negeri Jiran. Di negeri, tempat para TKI kita mengadu nasib, saya berdiri menuggu bis yang akan membawa saya ke Johor. Antrean agak panjang. Jauh di depan, ada beberapa orang berkulit gelap berbicara dalam bahasa Tamil. Menyusul sepasang suami istri sibuk mengatur dua anak mereka dalam bahasa Mandarin. Di belakang saya, ada serombongan ibu-ibu yang berbahasa Melayu dialek Malaysia. Agak jauh lagi berdiri beberapa pemuda yang berbicara dalam bahasa Inggris. Situasi multibahasa seperti ini bisa kita temui di berbagai tempat di tanah air kita, kecuali satu hal: masing-masing kelompok tidak saling menyapa dalam satu bahasa yang sama. Ketika saya menanyakan pukul berapa 'bas' akan berangkat, para ibu di belakang saya memuji kepandaian saya 'cakap Melayu'. Dari penampilan saya, mereka mengasumsikan bahwa semestinya saya fasih berbahasa Mandarin, dan karenanya kagum pada kemampuan saya belajar bahasa orang lain.

Dari dua pengalaman tadi, di Roma dan di negeri Jiran Malaysia, saya belajar dua hal tentang keragaman di Indonesia. Yang pertama, bahwa keragaman adalah hal yang tidak bisa kita anggap enteng, dan kedua, bahwa keragaman Indonesia diwarnai oleh interaksi lintas budaya yang menyatukan kita sebagai bangsa. Kedua hal ini sangat kuat terlihat dalam kesusasteraan Indonesia, sejak dari masa prakolonial hingga saat ini. Pada saat yang sama, keragaman yang mewarnai keindonesiaan juga bukannya tidak mengandungi sejumlah masalah. Makalah ini akan menyorot sejumlah persoalan keragaman yang perlu mendapat perhatian para pegiat bahasa dan sastra, khususnya lemahnya akses sastra antar daerah, ketimpangan penyebaran sastra dan jaringan sastra - terutama di wilayah Indonesia Timur. Pembahasan dalam makalah ini didasari oleh pemikiran bahwa kesusasteraan bukan hanya mencerminkan keindonesiaan, tetapi berperan penting untuk membentuk keindonesiaan itu sendiri. 


\section{Pembahasan}

\subsection{Keragaman dan Ketimpangan}

Penelitian filologi, sastra lisan dan sastra modern yang ditulis dalam aksara Latin sejak masa pra-kolonial tidak bisa tidak menunjukkan keragaman dalam kesusasteraan yang tersebar di kawasan Nusantara. Beribu naskah ditulis di atas lontar, deluwang dan kertas dalam macammacam aksara: aksara Pegon, Bugis, Batak, Jawa. Huruf Latin hanyalah salah satu jenis aksara yang setelah masuknya modernitas melalui berbagai hal - terutama kolonialisasi - menjadi dominan dan kemudian menggusur berbagai huruf tersebut. Ragam lisan dan tulis, yang hidup berdampingan, kemudian saling menunjang dalam proses yang disebut literasi sekunder - ketika yang lisan dituliskan, kemudian dilisankan kembali. Tetapi sekali lagi karena tuntutan modernitas, sastra lisan yang luput direkam dan dituliskan, dan kemudian tidak diturunkan pada generasi berikutnya, juga terancam kepunahan. ${ }^{1}$

Dari contoh-contoh di atas kita melihat bahwa keragaman tidak berada di ruang hampa, melainkan dalam suatu konteks sosial, politik, ekonomi yang mau tidak mau berpengaruh pada keragaman sastra. Pendidikan, yang berfungsi menyiapkan pembaca dan penulis, sangat berperan dalam memilih karya apa yang dibaca dan yang diproduksi. Dalam masa kolonial, sekolah Belanda mengajarkan dan menyediakan bacaan karya sastra Belanda, khususnya dari abad ke-19. Tidak mengherankan jika kemudian para sastrawan kita yang menulis di majalah Pujangga Baru mendapat pengaruh kuat dari penyair aliran romantik di Belanda yang disebut de tachtigers. Kebijakan budaya yang memprioritaskan hal yang satu dari yang lainnya, ikut berdampak pada perkembangan sastra. Satu lagi contoh dari masa kolonial adalah kebijakan pemerintah Belanda melalui badan kebudayaannya yang kemudian menjadi Balai Pustaka untuk memilih sastra dalam bahasa Melayu tinggi sebagai medium bersastra. Sebaliknya sastra yang ditulis dalam bahasa Melayu "pasar" atau Melayu lingua franka -- yang dipakai

\footnotetext{
${ }^{1}$ Untuk melihat kekayaan aksara dan naskah Nusantara dan sastra lisan lihat Sri Sukesi dkk (1997)., juga Uli Kozok (2009) dan Effendy (2008).
} 
sehari-hari oleh orang kebanyakan di Nusantara, dilabeli "sastra liar". Kebijakan ini mengandung kepentingan politik Belanda, karena sastra popular yang diterbitkan oleh penerbit-penerbit swasta dari berbagai kalangan itu sulit untuk dikontrol. Iklim politik pada waktu Perang Dingin di tahun 1960-an ikut tercermin dalam polarisasi sastrawan di Indonesia dalam aliran seni untuk seni dan seni untuk masyarakat (Moelyanto dan Taufiq Ismail, 1995). Ketika Orde Baru berjaya, maka karya sastra dan sastrawan dari aliran yang dianggap kekiri-kirian menjadi terpinggirkan.

Dari pembahasan di atas, kita melihat bahwa keragaman tidak pelak lagi mewarnai kesusasteraan Indonesia sejak masa prakolonial, dan terus berlanjut dalam dinamika yang berbeda-beda sampai saat ini. Namun kita juga melihat, bahwa keragaman tersebut tidak selalu berada dalam kesejajaran. Kebijakan budaya dan berbagai ketidakseimbangan struktural memengaruhi posisi kesusasteraan dalam masyarakat di tingkat lokal, nasional maupun global.

Di era kapitalisme global, keragaman dalam sastra tampak sangat dipengaruhi oleh persaingan bebas untuk merebut pasar pembaca.Arus penyebaran sastra di dunia diwarnai oleh ketimpangan pertukaran dari dunia yang maju secara ekonomi, ke dunia "ketiga". Penerjemahan kesusasteraan Indonesia ke bahasa Inggris jauh lebih sedikit dari penerjemahan karya dunia ke bahasa Indonesia. Di tingkat nasional, kesusasteraan dalam bahasa Indonesia lebih diminati oleh para penulis dan pembaca karena jangkauan pembaca lebih luas. Sastra daerah bersaing dengan sastra dalam bahasa Indonesia (sastra terjemahan, genre sastra populer dst.). Persaingan itu terjadi bersamaan dengan meningkatnya laju kepunahan bahasa-bahasa lokal.

Ketimpangan juga terjadi dalam penulisan sejarah sastra dan kajian sastra, yang masih berpusat pada karya sastra yang diproduksi di Jakarta dan pusat-pusat penerbitan di kota-kota besar di Jawa. Penulisan sastra dalam bahasa Indonesia di media masa lokal dan penerbitan lokal luput dari pengamatan para kritikus dan penulis sejarah sastra. Padahal,

\footnotetext{
${ }^{2}$ Untuk mendalami persoalan kebijakan kolonial, lihat tulisan Joris Jedamski, antara lain Jedamski (1992)
} 
kita semestinya sangat diuntungkan oleh keberadaan kantor bahasa dan balai bahasa di berbagai wilayah di Indonesia, yang seyogianya menjadi ujung tombak untuk mencatat dinamika sastra berbahasa Indonesia di tingkat lokal. Sayangnya, ada kebijakan yang membatasi perhatian balai dan kantor bahasa pada "sastra daerah" dalam arti sastra yang ditulis dalam bahasa-bahasa lokal, sedangkan lembaga di Pusat berorientasi pada kesusasteraan di tingkat nasional.

Ketimpangan lain terlihat dari jaringan sastrawan dan intelektual budaya yang merajut keindonesiaan. Aktifitas sastra (lisan maupun tulis) di wilayah Indonesia Timur kurang terekspos. Semakin ke Timur, relasi antar sastrawan dan komunitas sastra semakin menipis. Ketidaksejajaran dalam dinamika kesusasteraan Indonesia tidak bisa tidak menunjukkan ketimpangan struktural dalam bangun keindoensiaan itu sendiri. Jika demikian, apa peran sastrawan, kritikus sastra, peneliti, pembaca, komunitas sastra untuk membangun keindonesiaan yang lebih inklusif dan dengan demikian lebih kokoh?

\subsection{Pluralitas Inisiatif Pengayoman Sastra}

Di masa lampau kegiatan pengayoman, yang seringkali berarti pemberian dana dan sekaligus kontrol, lebih banyak dimainkan oleh negara, seperti pemerintah kolonial, dan penguasa pendudukan Jepang. Di era Orde Baru, pemerintah dan pemerintah daerah melalui dewan kesenian merupakan sponsor utama kegiatan sastra. Masa Orde Lama merupakan pengecualian, karena kemampuan pemerintah untuk mensponsori kegiatan sastra belum memadai, sementara persaingan untuk memaknai keindonesiaan dimainkan oleh partai politik dan lembaga kebudayaan yang digagas oleh masyarakat. Di era 2000-an, ketika Negara di hadapkan berbagai persoalan ekonomi dalam tatanan kapitalisme global, sokongan terhadap sastra juga semakin menyusut. Pada saat yang sama, selera konsumen sastra semakin beragam sehingga tidak mungkin lagi dipenuhi oleh satu lembaga pengayoman.

Berbagai inisiatif pengayoman sastra dari masyarakat pun muncul untuk menyalurkan kebutuhan penulis dan pembaca untuk mendapatkan kegiatan sastra yang sesuai dengan minat dan selera mereka. Komunitas sastra, yang mulai menjamur sejak akhir 1990-an di 
berbagai daerah di Indonesia, timbul-tenggelam, bermetamorfosis atau memecah diri untuk mengisi kebutuhan ekspresi, apresiasi dan idealisme untuk membangun Indonesia sesuai visi masing-masing. Salah satu contoh adalah komunitas Forum Lingkar Pena yang digagas oleh penulis Helvy Tiana Rosa untuk menjangkau penulis pemula mencatat jumlah anggota di atas 4000 di seluruh Indonesia, termasuk pekerja migran di mancanegara. Visi keindonesiaan yang Islami mencuat dari karya-karya FLP. Pada awal Reformasi di akhir 1990-an, Komunitas Sastra Indonesia memfasilitasi aspirasi kaum buruh untuk bersastra, dan sering melakukan aktifitas bersama Himpunan Penulis Yinhoa yang baru muncul setelah Orde Baru - dengan kebijakan yang melarang budaya dan sastra berbahasa Mandarin - tumbang. Komunitas Utan Kayu, yang digagas oleh penyair Goenawam Mohammad, membangun ruang diskusi dengan visi modernitas, dan kebebasan berekspresi. Sementara itu penyair Taufiq Ismail melalui lembar khusus siswa di Majalah Horison dan berbagai kegiatan berupaya meningkatkan apresiasi sastra di sekolah-sekolah. Perbedaan selera, orientasi budaya dan visi berbagai komunitas sastra ini seringkali bertumbuk dalam "pertikaian" dan serangan verbal. Pada saat yang sama, tekanan dari kelompok di luar sastra yang mengatasnamakan moralitas seringkali menjadi jenis sensor nonpemerintah terhadap kegiatan sastra.

Pluralitas pengayoman sastra juga terlihat dari berbagai jenis sayembara dan anugerah sastra yang didanai oleh budayawan dan masyarakat, seperti Hadiah Rancage untuk mendorong sastra dalam bahasa-bahasa daerah, Kathulistiwa Award dan Hadiah Pena Kencana. Pengayom yang tak kalah perannya di era otonomi daerah adalah koran dan media masa lokal yang menyalurkan kreatifitas lokal yang secara dinamis terus mengikuti perkembangan zaman. Generasi muda penikmat sastra yang lebih canggih memanfaatkan teknologi membuat terobosan baru untuk menyebarkan sastra melalui blog dan komunitas cyber-sastra.

\subsection{Keragaman Sastra dan Keindonesiaan}

Dari kegiatan sastrawan, budayawan, komunitas sastra, penerbit dan pelaku sastra sebagai agen perubahan, kita melihat bahwa Kesusasteraan tidak sekadar mencerminkan keragaman dan proses 
kebangsaan dari masa ke masa. Kesusasteraan juga ikut membangun keindonesiaan dengan berbagai cara. Pengarang dengan subyektifitasnya mengolah pengalamannya menjadi suatu bangun estetik dengan simbolsimbol, stereotip, wawasan dan ideologi, yang pada gilirannya ikut membangun wacana tentang keindonesiaan di masyarakat

Sejak masa prakolonial, berbagai ragam sastra yang diproduksi di Nusantara ikut berperan membangun landasan kebangsaan, baik melalui penggunaan bahasa, maupun dalam mengolah sumber daya budaya yang ada. Seperti pernah saya paparkan dalam esai tentang interaksi lintas budaya (Budianta, 2003), kesusasteraan berperan merajut kebersamaan dengan berbagai cara. Karya rekaan membayangkan dan menghadirkan berbagai wilayah satu negara, sehingga pembaca dapat mengalami dan merasa memilikinya. Kesusasteraan dalam berbagai bahasa di Nusantara, termasuk bahasa Melayu, merajut berbagai acuan budaya, mitos, legenda dan bahasa-bahasa Nusantara sehingga terjadi hibriditas lintas budaya (Budianta, 2008, Damono, 2009). Kesusasteraan mengolah interaksi lintas budaya dan persoalan-persoalan Indonesia, seperti membangun wacana tentang keindonesiaan atau mimpi (termasuk kritik dan mimpi buruk) Indonesia; menggali warna lokal, mitos, legenda luar dan urban dalam dinamika lokal-global; mengangkat persoalan identitas budaya (agama, suku, gender dan seksualitas, kelas) dalam proses mengIndonesia yang tak pernah selesai.

Sejak industri percetakan dan penerbitan muncul di Hindia Belanda, sastra yang ditulis dalam bahasa Melayu pasar (Melayu linguafranka) oleh penduduk Hindia Belanda keturunan Belanda, Tionghoa, atau suku lain, meletakkan dasar bagi perkembangan sastra dan keindonesiaan. Karya-karya itu berkontribusi mensosialisasikan bahasa Melayu sebagai sarana ekspresi sastra dan ikut merekat imajinasi tentang berbagai wilayah di Nusantara. Sastra yang dikategorikan sebagai bacaan liar tersebut menjadi sarana mendiskusikan pengalaman hidup sehari-hari di kawasan Hindia Belanda dalam bahasa yang dimengerti banyak orang.(Damono, 2004, Budianta, 2007).

Hibriditas lintas budaya sangat menonjol dalam kesusasteraan Indonesia sejak masa kolonial, dan sebelumnya. Sebuah majalah yang 
diterbitkan di tahun 1891, berjudul Cahabat Baik yang dikepalai (dan kemungkinan besar dihimpun dan dimotori sendiri) oleh seorang bernama Patmo di Soerijo dapat disebut sebagai satu contoh. Majalah ini mengumpulkan beraneka kisah, yang dituturkan dengan gaya tukang cerita yang bebas mengadaptasi berbagai sumber mancanegara, Arabpersia, Eropa, India, sastra lisan dan naskah dari nusantara (Budianta, 2006). Sapardi Djoko Damono (2009) menyebutkan bahwa sastra hibrid, yang mencampurbaurkan berbagai pengaruh lokal maupun global, merefleksikan hakikat keindonesiaan itu sendiri. Kesusasteraan yang berkembang di Nusantara dan kemudian menjadi Kesusasteraan Indonesia telah menunjukan kreatifitas lokal dalam menerjemahkan, mengadaptasi dan mengolah pengaruh lokal dan global untuk menjadi bentukan baru dengan warna tersendiri. Interaksi lintas budaya antar berbagai sumber budaya lokal terlihat dalam berbagai kreasi seni dan sastra di Nusantara. Sudah sering saya sebutkan, bagaimana seorang penulis dari Padang bernama Aman Datoek Majo'indo menciptakan ikon Si Doel anak Betawi, dan menjadi penulis pertama yang menggunakan ragam bahasa betawi dalam karya sastra Indonesia (2002)

Sastra, dalam hal ini, berfungsi sebagai medium lintas budaya yang ikut membangun keindoensiaan. Sastra Indonesia yang hibrid (penuh interaksi lintas budaya) mencerminkan dinamika masyarakatnya dari waktu ke waktu. Melalui interaksi lintas budaya seperti itu Ke-Indonesiaan dibangun secara dinamis dalam konteks yang semakin global. Perubahan zaman juga terlihat dari "hibriditas acuan bahasa dan budaya" dalam kesusasteraannya. Salah satu contoh menarik adalah novel Da Peci Code karya Ben Shohib yang menggambarkan pluralitas acuan budaya yang dihadapi oleh generasi muda Betawi yang "gaul" dalam latar cosmopolitan. Tatanan nilai dalam keluarga dan lembaga keagamaan bersaing dengan acuan yang diperoleh di universitas, media massa, internet, budaya populer, dan komunitas anak muda. Novel itu menampilkan percampuran bahasa Indonesia laras standar dan bahasa 'gaul' dengan alih kode kosa kata bahasa Arab, Inggris, dan Betawi (Budianta,2008). 


\subsection{Keragaman dalam Perkembangan Sastra Mutakhir}

Perkembangan sastra mutakhir menunjukkan dinamisme globallokal semacam itu, dalam suatu masyarakat majemuk yang terus bergerak. Gaya hidup kosmopolitan dan pengaruh global terlihat dari menjamurnya chicklit dan teenlit terjemahan maupun kreasi Indonesia. Fenomena ini ditunjang dengan popularitas majalah impor yang diadaptasi dengan muatan lokal seperti Cosmopolitan, Female yang menunjukkan selera generasi muda kelas menengah atas kosmopolitan. Pada saat yang sama kita melihat meningkatnya kebutuhan pembaca kelas menengah perkotaan yang berpendidikan tinggi untuk mencari bacaan popular yang lebih "cerdas", berwawasan luas. Popularitas karya Dewi Lestari dan Andrea Hirata yang mencapai tiras di atas 30.000 eksemplar menunjukkan meluasnya pasar pembaca di kalangan kelas menengah, terutama eksekutif muda. Demikian pula kebutuhan akan bacaan yang bernuansa Islami diisi oleh penerbit dengan genre-genre sastra romantis - didaktis yang disebut dengan "sastra dakwah, beberapa di antaranya meledak di pasaran, seperti novel Ayat-ayat Cinta. Penerbitan pribadi, teknologi Print on Demand dan distribusi melalui pembelian langsung ke konsumen (tanpa distributor) melalui internet merupakan suatu perkembangan baru dalam penyebaran karya sastra.

Berbagai genre sastra mendapat ruang yang berbeda-beda dalam dinamika sastra kontemporer. Genre prosa (novel dan cerpen) mendapat ruang terbesar dalam penerbitan dan media massa. Sebaliknya, genre puisi memiliki banyak peminat dan penulis, tetapi tidak mempunyai daya jual. Untuk menyiasati hal ini penyair memanfaatkan ruang gratis melalui blog atau menerbitkan buku puisi dengan pendanaan sendiri. Genre drama sebagai sastra tulis sulit mendapat ruang, sedangkan drama sebagai teater kurang mendapat dukungan pemerintah (seperti pada era 1970-an). Yang bertahan: Teater Koma, Gandrik dll (humor, satire politik yang dikemas secara populer dengan berbagai gaya lokal).

Sastra lisan dan seni pertunjukan mewakili sisi lain keragaman sastra yang kurang mendapat sorotan, namun di berbagai daerah masih mempunyai fungsi yang terkait dengan ritual, mata pencaharian dan kehidupan sehari-hari. Di perkotaan kreatifitas seni kolaboratif 
merupakan tren, misalnya dalam seni instalasi, teater dan seni pertunjukan multi-media. Alih wahana, baik ekranisasi (dari sastra ke film) maupun sebaliknya, menjadi peluang reproduksi sastra. Dalam tataran lintas negara, tren kolaborasi seni lintas bahasa dan budaya menyandingkan genre, mitos, legenda, dan acuan budaya yang berbedabeda. Kolaborasi seni tari dan teater Jepang dan Indonesia, pementasan La Galigo oleh sutradara Richard Wilson di Singapura, adalah beberapa contoh seni kolaboratif yang mengangkat sastra lokal ke panggung dunia.

Karya sastra Indonesia dalam berbagai genre, bahasa dan untuk khalayak pembaca yang berbeda-beda itu ditulis dalam gaya yang beragam, baik yang realis maupun romantis, yang absurd dan surealis, yang taat konvensi dan yang mengutamakan eksperimentasi bentuk dan gaya. Keberanian mendobrak yang semula ditabukan di era Orde Baru merupakan kecenderungan di era reformasi. Diskriminasi rasial, masalah sosial akibat perbedaan agama dan kelas, yang semula diredam melalui kebijakan SARA, kini tak jarang di angkat ke permukaan. Penulis perempuan mengangkat masalah gender, dan budaya patriarki, kekerasan terhadap perempuan, dan mengeksplorasi cara berbicara tentang seks dan seksualitas secara lebih terbuka. Beberapa tema lain yang mencuat setelah 1998 menunjukkan kesadaran politis yang tinggi. Dengan memaknai ulang sejarah Indonesia dari perspektif orang yang terpinggirkan, melontarkan kritik terhadap penyalahgunaan kekuasaan oleh penguasa, mengangkat pelanggaran kemanusiaan, kekerasan dan masalah-masalah urban, sastrawan mempertanyakan 'impian Indonesia" melalui mimpi buruk orang kebanyakan. Dalam keragamannya, sastra Indonesia mutakhir menghadirkan proses pencaharian dan pembentukan jati diri dan meneropong keindonesiaan yang kompleks dan penuh dinamika lintas budaya.

\section{Penutup}

Dalam keragamannya, karya sastra ikut bermain dalam pertarungan wacana tentang keindonesiaan, dan dengan demikian ikut berperan dalam proses demokratisasi yang sedang berproses, khususnya setelah 1998. Berbagai komunitas sastra membangun wacana dan visi 
keindonesiaan yang berbeda-beda, yang terus bersaing dan saling mengisi. Proses kebangsaan, yang dapat ditelusuri sejak masa prakolonial, merupakan suatu proses yang tak pernah berhenti. Dalam hal ini sastra menjadi medium pembelajaran publik tentang demokrasi dan keragaman Indonesia. Sastra berperan sebagai medium interaksi lintasbudaya dalam masyarakat yang majemuk, dan karenanya - seperti dikatakan Sapardi Djoko Damono - diwarnai oleh hibriditas.

Meskipun demikian, paparan di atas menunjukkan bahwa masih banyak ketimpangan dalam keragaman sastra di Indonesia. Untuk itu perlu dimungkinkan akses masyarakat terhadap karya sastra, terutama di wilayah yang terpencil dari segi lokasi dan jalur komunikasi. Sumber daya lokal, nasional, global (komunitas sastra, galeri, lembaga budaya asing, pemerintah daerah, pemerintah pusat, masyarakat pembaca, internet dan media massa) dapat dihimpun untuk menguatkan jaringan sastra se-Indonesia (khususnya di wilayah Timur), yang sampai saat ini masih sangat minim. Beberapa upaya lain mencakup hal-hal berikut:

- Memperkuat jaringan produksi-reproduksi sastra di seluruh wilayah (perpustakaan keliling, penerbitan, majalah lokal, rubrik sastra di koran lokal, sayembara, festival dan kegiatan sastra dan seni)

- Mendukung guru-guru sastra, mengupayakan apresiasi sastra yang dinamis dan menarik untuk generasi muda.

- Membuat sastra relevan dalam kehidupan generasi muda dengan pendekatan lintas disiplin, multidimensi dan multimedia.

- Mengupayakan penerjemahan sastra satu bahasa ke bahasa lain (baik dari bahasa "daerah" yang satu ke yang lainnya, juga dari bahasa-bahasa Inodnesia dan daerah ke bahasa Indonesia dan Inggris).

- Memperluas partisipasi masyarakat untuk melakukan kajian dan kritik sastra (resensi, tinjauan, diskusi) 
- Memanfaatkan Kantor Bahasa di berbagai wilayah untuk mendokumentasi semua kegiatan sastra (dalam berbagai bahasa: Indonesia dan bahasa lokal/asing yang ada di wilayahnya).

- Memanfaatkan teknologi (misalnya digitalisasi) yang terjangkau untuk mendokumentasikan sumber daya sastra yang ada

- Mengapresiasi aspek lintas budaya dalam kesusasteraan di berbagai wilayah (agar sastra bisa dimiliki oleh siapa saja yang ingin menulis dan mempelajarinya - bukan milik satu suku atau satu daerah saja)

- Mengeksplorasi sumber daya dan acuan budaya lokal sebagai sumber inspirasi (terbuka bagi pemaknaan baru maupun konservasi: keragaman pendekatan) dalam konteks global

Dengan berbagai upaya di atas, kita mewujudkan Indonesia yang lebih inklusif dan setara dalam keragaman.

\section{Daftar Pustaka}

Adiwimarta, Sri Sukesi dkk. (1997). Pendar Pelangi, buku persembahan untuk Prof. Dr. Achadiati Ikram, Jakarta, Fakultas Sastra UI dan Yayasan Obor Indonesia.

Budianta, Melani. (2002). "In the Margins of the Capital: Tjerita Boedjang Bingoeng and Si Doel Anak Betawi" dalam Clearing a Space: Postcoloniality and Indonesian Literature, eds. Keith Foulcher and Tony Day, KITLV.

(2003). "Sastra dan Interaksi Lintas Budaya," dalam festschrift , Cakrawala Tak Berbatas, Manneke Budiman dan Dhita Hapsarani (eds).

(2006). “Kolase Multikultural Sang Tukang Cerita: Cerpen Indonesia 1870an-1910an, dalam Nona Koelit Koetjing, Antologi Cerita Pendek Sebelum 1920, Sapardi Djoko Damono et al (eds), Jakarta: Pusat Bahasa, 2006, hal 1--3 
(2007). "Diverse Voices: Indonesian Literature and Nation-Building," in Language, Nation and Development in Southeast Asia; ed. Lee Hock Guan and Leo Suryadinata, Singapore, ISEAS, 2007, hal. 51--73.

Multikultural" dalam Kajian Wacana dalam Konteks
Multikultural dan Multidisiplin, Depok: FIBUI, hal 29--46.

Damono, Sapardi Djoko .(2004). Puisi Indonesia Sebelum Kemerdekaan: Sebuah Catatan Awal. Jakarta: Pusat Bahasa.

(2009). "Mengembangkan Sastra Hibrid": dipresentasikan dalam Seminar Strategi Kebudayaan dan Pengelolaannya, Ikatan Ahli Arkeologi Indonesia (IAAI), Komisariat Daerah Jabodetabek, 1 Juni.

Effendy, Tanas. (2008). Bujang Tan Domang, Sastra Lisan Orang Petalangan. Jakarta: Yayasan Obor Indonesia dan EFEO.

Jedamski, Doris. (1992). "Balai Pustaka-A Colonial Wolf in Sheep's Clothing," Archipel, 44, 1992, p. 23.

Kozok, Uli. (2009). Surat Batak, Sejarah Perkembangan Tulisan Batak Berikut Pedoman Menulis Aksara Batak dan Cap si Singamangaraja XII, Jakart: KPG dan EFEO,

Moeljanto, D.S. dan Taufiq Ismail. (1995). Prahara Budaya: Kilas-Balik Ofensif Lekra/PKI dkk. Yogyakarta: Mizan. 